\title{
ICT development on the example of selected software applied in manufacturing area
}

\author{
Agnieszka Szczotok $^{1, *}$, and Renata Dwornicka ${ }^{2}$ \\ ${ }^{1}$ Silesian University of Technology, Faculty of Materials Engineering and Metallurgy, \\ Z. Krasinskiego Str. 8, 10-019 Katowice, Poland \\ ${ }^{2}$ Cracow University of Technology, Institute of Applied Informatics, Al. Jana Pawła II 37, 31-864 \\ Cracow, Poland
}

\begin{abstract}
This paper provides an insight into a few selected aspects of computer-aided software usage in the manufacturing processes. This research aims to point out a diversity of software used in manufacturing area which is available on the market and to summarize most of the functionalities of three selected types of software for production zone backing.
\end{abstract}

\section{Introduction}

Nowadays, we can observe a geographic increase in the number of individuals, producers and companies, as well as growing availability of distribution channels for products (e.g. online shopping, web enterprise management, etc.). It is related to the evolution of ICT (Information and Communication Technologies) and its increasing effect in the business world. ICT generally includes any communication device or application, including but not limited to radio, television, cellular phones, computer and network, hardware and software, satellite systems, and etc, as well as various services and applications associated with them, such as videoconferencing and distance learning. ICT has changed the concept of market place, buying and selling habits of consumers, advertising media, business operations and many more. ICT is most often used in mass production, as computer control makes it possible to produce many identical items very quickly. But ICT is also useful in small batch and even one-off work, because computer control enables complicated shapes to be produced more accurately than made by hand. ICT is used in manufacturing high quality products and it reduces the cost of production by minimizing the use of human labour in many industries and businesses. The importance of the ICT sector within OECD economies has been growing over the 1990s.

Digital technologies and access to high-speed broadband positively impacts the operations and profitability of all businesses across just about every industry and business type. Since high quality products are manufactured at low cost, people can buy good quality products at a relatively low price.

Quality control systems utilize production line information. They need visualization methods, data mining technologies, and statistical process control to analyze and improve

\footnotetext{
* Corresponding author: agnieszka.szczotok@polsl.pl
} 
quality of products. The background for these functions is provided by ICT according to Fig. 1.

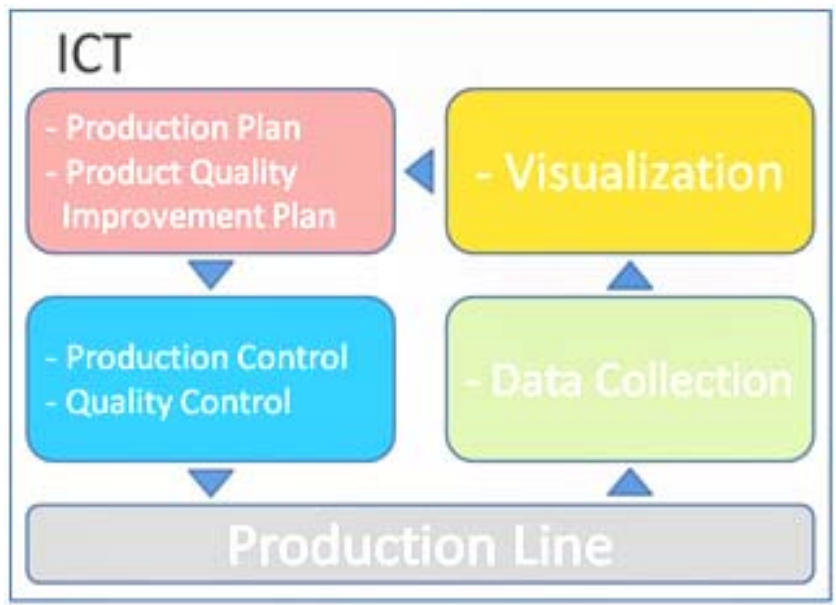

Fig. 1. Integration of quality management in the production zone with ICT.

An ICT system is a set-up consisting of hardware, software, data and the people who use them. It commonly includes communications technology, such as the Internet.

This paper presents the application of ICT in the range of software area to improve productivity and product quality through the development of production management systems is presented. The selection of examples of software in manufacturing application presented in the article was not random. The authors' intention was to point out a diversity of software used in manufacturing area that is available on the market and to summarize most of the functionalities of three selected types of software for production zone backing.

\section{Overview of selected software}

\subsection{Impuls EVO}

The first example of the presented software is Impuls EVO created by BPSC company [1]. This software is an example of the integrated MRPII/ERP class system. In the production area the software provides two functionalities: Discrete Manufacturing and Process Production.

The first one mentioned here enables: production planning for different periods of time, reflection of the multi-level structure of product, calculating technical production cost margin for different product configurations according to the technology and different calculation algorithms, real time management of the whole production process, as well as registration of tasks according to work cards, touch screens and the MES system.

The second functionality - Process Production - consists of the following possibilities: representation of material flow in the full structure of departments and production warehouses, freely chosen number of alternative recipes for every product, tree-type structure of recipes, registration and a precise analysis of the product path (traceability), planning tools that allow creation of tasks for job positions in production routes, estimation of cost of production and reacting to changes in prices of resources or production technologies, as well as supporting the fulfillment of HACCP system's requirements.

Undoubtedly an advantage of Impuls EVO software is a solution which makes it possible to connect majority of the external solutions functioning on the market. Usually 
they are tools for a limited, narrow field and clients are used to them. Among such solutions there are for example billing programs, B2B or B2C. Thanks to the integration of such solutions with the ERP system the management of all processes in the company will be conducted more comprehensively.

\subsection{MONACO ${ }^{\circledR}$}

MONACO ${ }^{\circledR}$ is created by the company GT Systems 2 company [2]. It is a specialized software tool for record-keeping, archiving and creation of technical documentation for manufacturing enterprises. The concept technical documentation is not understood only as a set of computer data needed for correct production planning and management in ERP systems, but it covers a much greater scope, e.g. Items, Drawings, Bills of materials, Technological procedures, Inputs - outputs (tools, additional material...), Technological regulations (testing, welding...), Measuring and control regulations (CAQ,...), CAD Models, Technical regulations (constructions), Technical specifications - requirements of customers, Technical specifications - catalogues, Service regulations, Projects (works schedules), Calculations (reviews of expenses).

In the production zone $\mathrm{MONACO}^{\circledR}$ is a tool used especially for effective: offer proceeding (creation of preliminary technical designs, estimates of expenses and terms, preliminary specification of required inputs - material and production needs); production planning (creation of items, bills of materials, technological procedures, requirements regarding capacity); production (creation of production documentation - drawings, operations sketches, regulations, tools equipment, regulations for quality management (CAQ), etc.).

\subsection{Tecnomatix}

Tecnomatix is an example of digital manufacturing solutions that help to digitalize manufacturing and the process of transforming innovative ideas and raw materials into real products [3]. With Tecnomatix software, it is possible to design and configure 3D factory layouts for efficient factory operations using an integrated line planning environment, synchronize process design to deliver better plans, conduct assembly simulation for virtual verification of all the process operation steps and their details defined in manufacturing plans, optimize production logistics and material flow, integrate electronic work instructions with manufacturing planning, and even program and simulate robots. All these functionalities help to maximize production efficiency.

\section{Discussion}

When selecting the computer-aided quality control system, clients first focus on the functionality and capabilities of the production part. This is of key importance to them. A specification of clients' requirements emphasizes this part of the system. The company which plans to implement ICT, especially in the production zone, should most importantly, check how their business processes are conducted in this area and have a closer look at them.

ERP Impuls EVO supports scheduling and management of process production comprehensively. Thanks to the connection between a logistic chain, production processes, and a financial flow it is possible to improve the level of customer service and to rationalize of ordering and performance of contracts together with production optimization.

MONACO ${ }^{\circledR}$ technical information system gives possibilities for integration with ERP and CAD systems as well as commercial policy of the company. The system offers tools for 
keeping basic requirements for technical documentation: precision - quality (the more precise and "truer" the documentation is, the smoother and more floating the production is); documentation elaboration speed (its creation should take as little time and means as possible; at the same time the technical documentation department should provide information at the right time); generality (the system enables creation of technical documentation with an aim to minimize changes of "non-technical" nature, e.g. materials changes, swaps of departments, swaps of capacities - machines, etc.); portability (production shifting between respective plants or corporations should not have any influence, or only minor one, on technical documentation).

Tecnomatix connects the disciplines of planning and engineering with automation and control to create a smart factory model with all of the production process details, including the automation hardware and software.

On the other hand, it should be noted that such systems have numerous limitations in interfaces between them and other management systems utilized in industry e.g. environmental management [8]. The support for R\&D is also limited only to the recordkeeping without built-in analytical tools e.g. very interesting interdisciplinary investigations involving academia and industry (e.g. interviewed authors of the long-term research from biotechnological branch [9-13], materials science [14-19]) only hardly may be supported by these tools. In a consensus opinion, the interviewed authors believed that more sophisticated analytical tools must be provided from the outside and individually adapted to the nature of the their work, regardless of whether they are directly related to the optimization of production [20,21] or research [22-25].

The functionalities of the analyzed software pointed in the work indicate many possible benefits for a manufacturer from having ICT tools available on the market. The results suggest both efficiency and economical gains through an increased usage of ICT tools.

\section{Conclusion}

Thanks to digital manufacturing solutions it is possible to improve management on all decision-making levels. Such solutions support effectiveness and efficiency, lower the costs of activity and increase its profitability.

Having analyzed the presented types of software and their functionalities for manufacturing, it is therefore considered that the knowledge of possibilities of the various commercially available types of software is necessary to decide which functionalities could be the best options for a particular manufacturing process. The ideal software application could require a connection of various functionalities from different types of software to meet all wants and needs.

Among the advantages of ICT the producers frequently point e.g. [4-7]: time and labor costs reduction and production increase, greater consistency and accuracy in production, systematic growth of capacity, safety of the workers involved, quality of the final product, improvement of customer service, possibility of making complex predictions quickly, and ability to communicate and work globally. It seems to be possible to achieve these goals in the case of taking into account the specificity of the particular industry and enterprise during selection and implementation of the manufacturing software.

\section{References}

1. BPSC homepage. http://www.bpsc.com.pl/

2. GT Systems 2, s.r.o. homepage. http://www.gtsystems $2 . s k$ 
3. Siemens Product Lifecycle Management Software Inc. homepage. http://www.plm.automation.siemens.com

4. K. Czech-Dudek, Mechanik, 7, 149 (2015)

5. M. Miecielica, W. Wiśniewski, Computer-aided design of technological processes (PWN Publisher, Warszawa, 2005)

6. R. Sirirattrakul, Capacity Building Workshop on Information Society Statistics: Infrastructure, Household and other Indicators (Bangkok, 2007)

7. Thailand National Statistical Office, Measuring the impact of ICT use in business: the case of manufacturing in Thailand (UNCTAD, New York and Geneva, 2008)

8. A. Pacana, R. Ulewicz, Polish J. Environ. Studies, 16, 165 (2017)

9. L. Skrzypczak, E. Skrzypczak-Pietraszek, E. Lamer-Zarawska, B. Hojden, Acta Soc. Bot. Pol., 63, 173 (1994)

10. E. Skrzypczak-Pietraszek, J. Pietraszek, Acta Biol. Crac. Ser. Bot., 51, 62 (2009)

11. E. Skrzypczak-Pietraszek, J. Pietraszek, Chem. Biodivers., 11, 562 (2014)

12. E. Skrzypczak-Pietraszek, New Biotech., 33, 155 (2016)

13. E. Skrzypczak-Pietraszek, I. Kwiecien, A. Goldyn, J. Pietraszek, Phytochem. Lett., 20, 443 (2017)

14. T. Pieczonka, J. Kazior, A. Tiziani, A. Molinari, J. Mater. Process. Technol., 64, 327 (1997)

15. N. Radek, K. Bartkowiak, Proc. Sixth Int. Wlt Conf. on Lasers in Manufacturing, , Physics Procedia Vol. 12 (Munich, Germany, 499, 2011)

16. T. Pieczonka, J. Kazior, A. Szewczyk-Nykiel, M. Hebda, M. Nykiel, Powder Metall., 55, 354 (2012)

17. R. Ulewicz, P. Szataniak, F. Novy, Proc. $23^{\text {rd }}$ International Conference on Metallurgy and Materials (Brno, Czech Republic, 784, 2014)

18. P. Szataniak, F. Novy, R. Ulewicz, Proc. $23^{\text {rd }}$ International Conference on Metallurgy and Materials (Brno, Czech Republic, 778, 2014)

19. N. Radek, A. Sladek, J. Broncek, I. Bilska, A. Szczotok, Adv. Mat. Res.-Switz., 874, 29 (2014)

20. J. Pietraszek, Proc. $11^{\text {th }}$ Int. Conf. on Artificial Intell. and Soft Comp. (ICAISC), Lect. Notes. Artif. Int. 7267 (Zakopane, Poland, 310, 2012)

21. J. Pietraszek, E. Skrzypczak-Pietraszek, Adv. Mat. Res.-Switz., 874, 151 (2014)

22. T. Styrylska, J. Pietraszek, ZAMM-Z. Angew. Math. Mech., 72, T537 (1992)

23. J. Pietraszek, A. Gądek-Moszczak, T. Torunski, Adv. Mat. Res.-Switz., 874, 139 (2014)

24. N. Radek, J. Pietraszek, B. Antoszewski, Adv. Mat. Res.-Switz., 874, 29 (2014)

25. A. Gadek-Moszczak, J. Pietraszek, B. Jasiewicz, S. Sikorska, L. Wojnar, Proc. $6^{\text {th }}$ Int. Conf. on Comp. Collective Intell. (ICCCI) (Seoul, South Korea, 127-136 2014) 